Gilles Plourde MD FRCPC, Pierre-Paul Barry MD FRCPC, Luc Tardif MD FRCPC, Yves Lepage PhD, Jean-François Hardy MD FRCPC

\title{
Decreasing the toxic potential of intravenous regional anaesthesia
}

In an attempt to reduce the dose of local anaesthetic agent during intravenous regional anaesthesia (IVRA) of the upper limb, we have used a forearm tourniquet in 12 adult volunteers. The volume of the forearm venous system was predetermined angiographically. We performed IVRA with three solutions of lidocaine $(0.25,0.375,0.5$ per cent) administered in a volume equal to the forearm venous system. Angiographic results indicate that: a forearm tourniquet provides adequate vascular isolation; the volume of the forearm venous system can be correlated with body weight; the progression of the fluid in the venous system follows a pattern that is similar for all patients with the small veins of the distal forearm and proximal hand being filled last. With this technique, lidocaine 0.5 per cent resulted in a dose of $1.5 \mathrm{mg} \cdot \mathrm{kg}^{-1}$ and provided excellent analgesia. Lower concentrations were unsatisfactory. We conclude that the use of a forearm tourniquet allows reduction of the local anaesthetic dose to a non-toxic level and thus increases the safery of IVRA.

\section{Key words}

ANAESTHETIC TECHNIQUES: regional, intravenous; ANAESTHETICS, LOCAL: lidocaine; COMPLICATIONS: arrythmia, convulsion; TOXICITY: local anaesthetics.

From the departments of Anaesthesia and Radiology, Maisonneuve-Rosemont Hospital, and the department of Mathematics and Statistics, University of Montreal, Montreal.

Address correspondence to: Dr Jean-François Hardy, Departement d'Anesthésie-Réanimation, Hôpital

Maisonneuve-Rosemont, 5415 boul. de l'Assomption, Montréal, Qc H1T-2M4.

Presented at the 1986 Annual Meeting of the Canadian Anaesthetists' Society in Montreal, Québec.
The main complications associated with IV regional anaesthesia (IVRA) result from the sudden introduction of a toxic amount of local anaesthetic (LA) into the systemic circulation. It is desirable to use a LA of minimal toxicity and to limit the amount administered to the least compatible with satisfactory analgesia. ${ }^{\prime}$ Lidocaine and prilocaine appear to be the safest agents. ${ }^{2}$ Bupivacaine should not be used because of potential cardiotoxicity. ${ }^{3}$ Determination of the minimal effective dose is more complex. For lidocaine, the most common agent, $3 \mathrm{mg} \cdot \mathrm{kg}^{-1}$ administered as a 0.5 per cent solution ensures adequate anaesthesia when used with the tourniquet placed on the upper $\operatorname{arm}^{2,4}$ but this dose carries the risk of systemic toxicity. The dose can be reduced to $1.5 \mathrm{mg} \cdot \mathrm{kg}^{-1}$ if 20 min ischaemia precede the injection. ${ }^{2}$ Urban $^{5}$ used a similar dose of lidocaine administered as a 0.25 per cent solution and reported inadequate analgesia. The use of a forearm tourniquet with lidocaine 0.5 per cent $\left(2 \mathrm{mg} \cdot \mathrm{kg}^{-1}\right.$ ) provided adequate analgesia for normotensive patients. ${ }^{6}$ Although 0.5 per cent solutions appear universally effective, the differential effects of volume, concentration and total dose are not known. For prilocaine the optimal dose is $4 \mathrm{mg} \cdot \mathrm{kg}^{-1}$ preceded by $15 \mathrm{~min}$ ischaemia. ${ }^{2}$

We evaluated the effectiveness of placing the tourniquet on the forearm instead of on the upper arm to reduce the volume and dose of LA.

We attempted to answer the following questions to determine the minimum requirement of LA in the adult: 1 What is the volume of the forearm venous system?

2 With the above volume what is the minimal effective concentration of lidocaine?

\section{Methods}

Informed consent was obtained from all subjects.

\section{Volume determination}

Twelve healthy volunteers (members of our department, six males, six females) participated. A 20 ga teflon catheter was inserted in a dorsal vein of the hand and used for injection of contrast material (Hexadrix ${ }^{\text {TM }}$ viscosity: 7.20 centipoise at $37^{\circ} \mathrm{C}$ ). A similar cannula was inserted in the ipsilateral radial vein for pressure recording during the injection (Bentley Trantec transducer linked to a Tektronics monitor model 414). After placement of an 8 
cm well-padded surgical cuff $1 \mathrm{~cm}$ below the elbow, the forearm was exsanguinated with an Esmarch bandage and the cuff inflated $100 \mathrm{mmHg}$ above systolic blood pressure. The injection of contrast medium was then started at a rate not exceeding $0.25 \mathrm{ml} \cdot \mathrm{sec}^{-1}$, under constant fluoroscopic control, and videotaped. The infusion was interrupted whenever the pressure within the venous system approached cuff pressure. A constant infusion system was not used because it is not generally used in clinical practice. The injection was stopped when the radiologist judged the venous system to be full on the basis of venous distension.

The volume of the forearm venous system was measured as the volume necessary to fill the venous system completely without producing venous distension and was determined by independent review of the videotapes by two investigators (GP, JFH). The criterion for complete filling was the absence of progression of contrast material in a new territory. Results were analysed with the least square linear regression.

\section{Concentration determination}

Twelve healthy volunteers (six males, six females, nine of whom were enrolled in the first study) participated. The venous block was performed, using the technique above except that (1) only one cannula was inserted, on the dorsum of the hand; (2) the volume injected was based on angiographic findings (see results); (3) the solution injected consisted of lidocaine $0.5,0.375$ or 0.25 per cent administered in a double-blind, random order such that each concentration was used twice for each sex (pseudorandomization). Neurological assessments were carried out at 2, 5, 10,15 and $20 \mathrm{~min}$ after the end of the injection.

Pinprick and light touch perception were assessed in five different areas of the hand: 1 , dorsal first web space (superficial branch of radial nerve); 2, index finger tip (digital branch of median nerve); 3 , thenar eminence (palmar cutaneous branch of median nerve); 4, little finger tip (digital branch of ulnar nerve); and 5, hypothenar eminence (palmar cutaneous branch of ulnar nerve). ${ }^{5}$ Vibration $(128 \mathrm{~Hz})$ and position sense were tested at the base of the index finger (second metacarpophalangeal joint). Scoring was binary throughout.

Motor function assessment included the following muscles: flexor digitorum superficialis (second finger, median nerve); extensor digitonum (second finger, radial nerve); opponens pollicis (median nerve); first dorsal interosseous (abduction of the index, ulnar nerve); second palmar interosseous (abduction of the index, ulnar nerve). All testing was done in strict conformance with accepted procedure ${ }^{10}$ with muscle power graded on a 0 to 5 scale $(0$ : no contraction; 1: trace of contraction, 2 : active movement with gravity eliminated, 3: active movement against

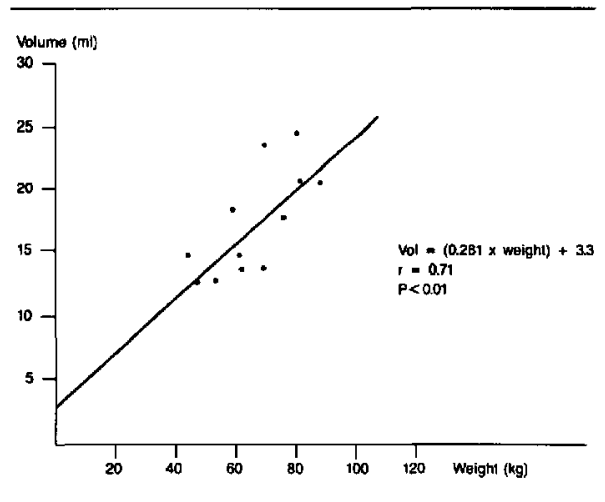

FIGURE 1 Relationship between filling volume of forearm venous system and body weight.

gravity, 4: active movement against gravity and resistance, and 5: normal power). All subjects had normal baseline neurological function.

\section{Results}

\section{Volume}

The mean volume injected was $17.7 \mathrm{ml}(\mathrm{SD}=4.7)$. The volume correlated $(P<0.01)$ with body weight $(r=$ $0.71)$, height $(r=0.73)$, volume of forearm ( $r=0.79)$ and length of forearm $(r=0.81)$. Figure 1 illustrates the relation between filling volumes and weight.

A consistent filling flow pattern emerged (Figure 2). The veins immediately below the cuff were the first to be filled (Figure 2a), followed by the palmar arcade and digital veins (Figure 2b). Veins of the distal forearm and proximal hand filled last (Figure $2 \mathrm{c}$ ). It seems that the diameter of the vein was the major determinant of the filling order, with the smaller veins being filled last. We observed no leak of contrast medium or congestion of the limb during the injection.

Pnessure recordings showed a poor correlation with the volume injected. The pressure was near 0 until the contrast medium reached the venous channels containing the cannula used for the recording. This usually took between one and ten seconds. The pressure thereafter was dependent on the rate of injection, particularly during the early phase of the injection with pressures up to 250 mmHg being attained easily. These pronounced fluctuations of pressure became less important towards the end of the injection.

\section{Concentration}

The effect of the concentration of lidocaine on analgesia is 


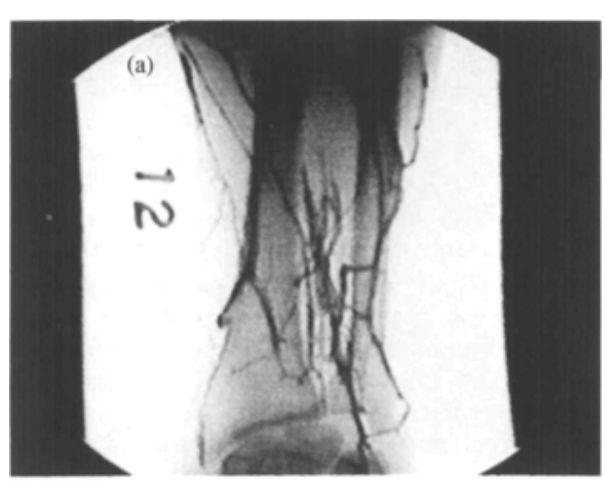

\section{Residual sensation to pinprick (5 areas)}
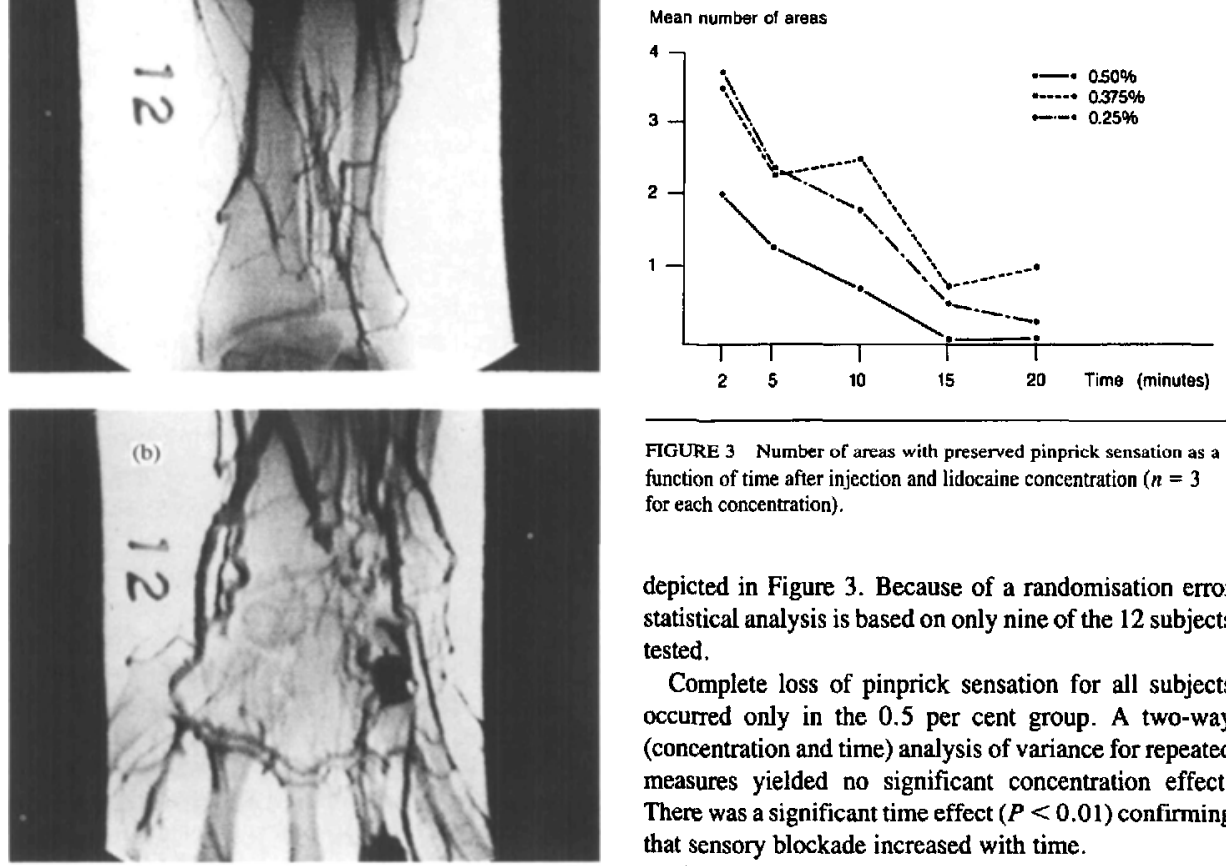

FIGURE 3 Number of areas with preserved pinprick sensation as a function of time after injection and lidocaine concentration $(n=3$ for each concentration).

depicted in Figure 3. Because of a randomisation error statistical analysis is based on only nine of the 12 subjects tested.

Complete loss of pinprick sensation for all subjects occurred only in the 0.5 per cent group. A two-way (concentration and time) analysis of variance for repeated measures yielded no significant concentration effect. There was a significant time effect $(P<0.01)$ confirming that sensory blockade increased with time.

The effects of 0.5 per cent lidocaine on motor function

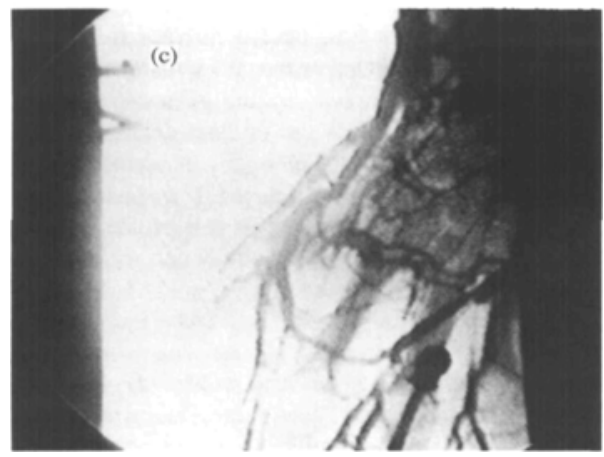

FIGURE 2 Fluoroscopic images of the filling pattem of the venous system of the hand, wrist and forearm. Limb orientation is the same for all frames. Large veins of the forearm were the first to be filled (a), followed by the palmar arcade and digital veins (b). Small veins of the distal forearm and proximal hand filled last (c)

is depicted in Figure 4. The other concentrations will not be considered since they do not appear to provide adequate analgesia. Movements mediated by intrinsic hand muscles (opposition, abduction, adduction) were markedly attenuated at ten minutes. Movements mediated by extrinsic muscles (finger flexion and extension) were relatively well preserved up to the $20 \mathrm{~min}$ observation period.

Congestion of the hand was noted in two male patients immediately after vigorous pronation/supination movements in the course of motor testing. These two patients were tested a few days later with careful avoidance of supination and pronation movements and no congestion was observed. Only results from the repeat session were used.

\section{Discussion}

This study was undertaken to determine the absolute minimal dose of lidocaine required to perform a venous block. The results indicate that with the use of a forearm tourniquet, $1.5 \mathrm{mg} \cdot \mathrm{kg}^{-1}$ lidocaine $(0.5 \%$ solution) is 


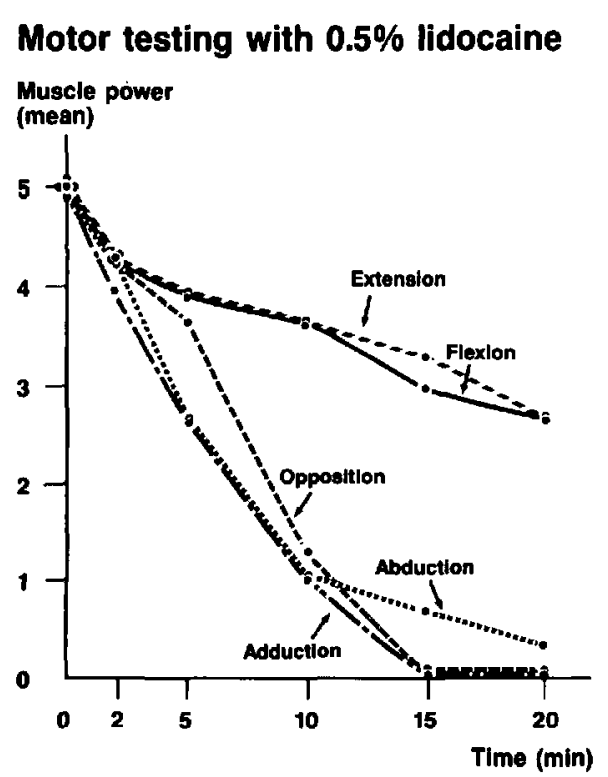

FIGURE 4 Muscle power as function of time after injection of 0.5 per cent lidocaine $\left(1.5 \mathrm{mg} \cdot \mathrm{kg}^{-1}\right)(n=3)$.

sufficient to produce adequate anaesthesia. This approach virtually eliminates the risk of local anaesthetic toxicity in the advent of tourniquet failure.

The use of a tourniquet below the elbow, as well as below the knee, is generally discouraged because of a greater risk of nerve injury or of vascular leaks due to the bi-osseous structures of these extremities. ${ }^{7}$ These fears have not been substantiated by systematic studies. Excessive tourniquet pressure appears to be the main factor in producing nerve injury ${ }^{8}$ and one might logically conclude that placing the tourniquet above rather than below the elbow poses a threat to the radial nerve which is vulnerable as it circles around the humerus. ${ }^{9}$ We have found no study of the influence of tourniquet site on the incidence of venous or arterial leaks. Finally the use of a forearm tourniquet, although infrequent, reportedly causes no untoward effect. ${ }^{1,6}$

Study of the effects of the concentration of lidocaine on analgesia was complicated by a randomization error which reduced the number of observations. Adequate analgesia in all subjects at $15 \mathrm{~min}$ was observed only with the $\mathbf{0 . 5}$ per cent lidocaine group suggesting that more dilute solutions are inadequate. The number of observations is too small for definitive statistical analysis. Additional subjects would be required to evaluate the effect of concentration. This drawback is not of major importance since the lidocaine requirement based on the volume of the forearm venous system remains below the toxic IV dose even when the 0.5 per cent solution is used.

The angiographic part of the study led to interesting observations. First, the volume of the forearm venous system can be adequately estimated with a variety of anthropometric measures, including body weight which is the most convenient. Second, the progression of the fluid within the venous channels follows a consistent flow pattern determined by the size of the vessels, with the larger veins being filled first and the smaller veins last. This can be explained in terms of Laplace's law which states that, at equal pressure, tension of the wall of a cylinder is proportional to the radius of that cylinder. Larger wall tensions will result in more dilated vessels, thus increasing the probability of valve failure which is required for fluid progression. Third, a forearm tourniquet prevents leakage of the contrast medium into the systemic circulation. Fourth, a forearm tourniquet provides adequate occlusion of the arterial flow in the absence of pronation and supination movements which is the likely cause for the venous congestion observed during motor testing.

Since the viscosity of the contrast medium is much higher than that of the LA solution (ratio 7:1), to what extent can the above conclusions be applied to the injection of local anaesthetics? There is no published information on this problem. When the venous system is filled and the liquid is stationary with respect to the walls, the viscosity is an unimportant variable in determining the filling volume. Preliminary dimensional analysis suggests that, at a constant filling pressure, increased viscosity will prolong filling time but flow pattern should be the same, provided that the inertia of the veins has a negligible effect on the mechanics of the process. The absence of leakage of contrast medium under the tourniquet can probably be extrapolated to LA solutions since viscosity is not important under static conditions (BG Newman, personal communication).

Serial determinations of serum concentration of lidocaine by Chan ${ }^{6}$ during performance of an IV block with a forearm tourniquet revealed only minimal leakage of lidocaine which was insufficient to compromise either patient safety or quality of analgesia, further confirming adequate venous occlusion.

We have since performed over 100 IVRAs with a forearm tourniquet and 0.5 per cent lidocaine using the volume derived from this experiment $(0.3 \mathrm{ml} \cdot \mathrm{kg}+3 \mathrm{ml})$. 
All patients had satisfactory analgesia and no toxic reaction or limb congestion was observed.

We conclude that satisfactory venous block can be produced by using a forearm tourniquet and $1.5 \mathrm{mg} \cdot \mathrm{kg}^{-1}$ of lidocaine 0.5 per cent. This approach greatly reduces the risk of LA toxicity and makes the IV block technique safer.

\section{Acknowledgments}

The authors wish to thank Christiane Côté BScInf. for technical assistance, Sylvie Le Breux for typing the manuscript, and all the volunteers for their kind and patient cooperation.

We are indebted to Professor Barry G. Newman for his expert advice on fluid dynamics.

\section{References}

1 Thorn-Alquist AM. Intravenous regional anaesthesia a seven year survey. Acta Anaesth Scand (Suppl) 1971; 15: 23-32.

2 Harris WH, Slater EM, Bell HM. Regional anesthesia by the intravenous route. JAMA 1965; 194: 105-8.

3 Heath ML. Bupivacaine toxicity and Bier blocks. Anesthesiology 1983; 59: 481.

4 Mazze RI, Dunbar RW. Plasma lidocaine concentrations after caudal, lumbar epidural, axillary block and intravenous regional anesthesia. Anesthesiology 1966;27: 574-9.

5 Urban BJ, McKain CW. Onset and progression of intravenous regional anesthesia with dilute lidocaine. Anesth Analg 1982; 61: 834-8.

6 Chan CS, Pun WK, Chan YM. Intravenous regional analgesia with a forearm tourniquet. Can $J$ Anaesth 1987; 34: 21-5.

7 Sanders $R$. The toumiquet, instrument or weapon? The Hand 1973; 5: 119-23.

8 Bolton CF, McFarlane RM. Human pneumatic tourniquet paralysis. Neurology 1978; 28: 787-93.

9 Dornette WHL. Compression neuropathies: medical aspects and legal implications. In: Neurological and Psychological Complications of Surgery and Anesthesia. BJ Hindman (Ed.). International Anesthesiology Clinics 1986; 24: 201-29.

10 Medical Research Council. Aids to the examination of the peripheral nervous system, London, Her Majesty's Stationery Office. 1976; Memorandum \#45.

\section{Résumé}

Afin de réduire la dose d'anesthésique local lors du bloc veineux (BV) du membre supérieur, nous avons étudié l'utilisation d' un tourniquet sur l'avant-bras chez 12 volontaires. Nous avons effectué des $B V$ avec trois concentrations de lidocaine $(0.25,0.375,0.5$ pour cent), utilisant un volume d'anesthésique local égal au volume du réseau veineux de l'avant-bras précédemment déterminé par angiographie. Les données angiographiques montrent que: le tourniquet placé sur l'avant-bras assure un blocage vasculaire adéquat; le volume du réseau veineux de l'avant-bras peut être prédit à partir du poids corporel; la progression du liquide dans le réseau veineux suit une séquence uniforme d'un patient à l'autre, les petites veines de l'avant-bras distal et de la main se remplissant les dernieres. L'utilisation de lidocaine 0.5 pour cent avec cette technique résulte en une dose totale de $1.5 \mathrm{mg} \cdot \mathrm{kg}^{-1}$ et produit une excellente analgésie. Nous concluons que l'usage d'un tourniquet sur l'avant-bras réduit le risque d'intoxication a l'anesthésique local et contribue à rendre plus sécuritaire I'anesthesie régionale intraveineuse avec la lidocaine. 